\title{
ESTRESSE SALINO E TEMPERATURAS NA GERMINAÇÃO E VIGOR DE SEMENTES DE Chorisia glaziovii O. Kuntze ${ }^{1}$
}

\author{
ROBERTA SALES GUEDES², EDNA URSULINO ALVES³, EVIO ALVES GALINDO4; \\ LEANDRA MATOS BARROZO ${ }^{4}$
}

\begin{abstract}
RESUMO - Chorisia glaziovii O. Kuntze, espécie nativa do Nordeste brasileiro, pertencente à família Bombacaceae têm usos diversificados na medicina popular, na recomposição de áreas degradadas e na indústria de estofados. Assim, objetivou-se com o trabalho avaliar o efeito do estresse salino e temperaturas na germinação e vigor das sementes de $C$. glaziovii. As soluções salinas foram preparadas utilizando-se como soluto o $\mathrm{NaCl}$, nas concentrações: 0,0 (controle); 1,5; 3,0; 4,5 e 6,0 dS.m ${ }^{-1}$ diluídas em água destilada e deionizada. Posteriormente as sementes foram distribuídas no substrato e postas para germinar nas temperaturas constantes de $25^{\circ} \mathrm{C}, 30{ }^{\circ} \mathrm{C}, 35$ ${ }^{\circ} \mathrm{C}$ e alternada de $20-30{ }^{\circ} \mathrm{C}$. O delineamento experimental utilizado foi o inteiramente ao acaso, com os tratamentos distribuídos em esquema fatorial 5 x 4 (níveis de salinidade e temperaturas), em quatro repetições de 25 sementes. Avaliou-se a porcentagem, primeira contagem e índice de velocidade de germinação, bem como o comprimento de plântulas (raiz e parte aérea). $\mathrm{O}$ aumento da concentração salina no substrato provocou redução na germinação e no vigor das sementes de C. glaziovii, especialmente na temperatura de $30^{\circ} \mathrm{C}$ e $35^{\circ} \mathrm{C}$. Na temperatura de $25^{\circ} \mathrm{C}$ e 20 $30{ }^{\circ} \mathrm{C}$ a germinação e o vigor das sementes são menos afetados pelo estresse salino. $\mathrm{O}$ estresse salino ocasionado por $\mathrm{NaCl}$ até o potencial de 4,5 dS.m-1 não afeta o desempenho germinativo de sementes de C. glaziovii, a qual desenvolveu elevada tolerância à salinidade.
\end{abstract}

Termos para indexação: barriguda, sementes florestais, salinidade, análise de sementes.

\section{WATER STRESS AND TEMPERATURE EFFECTS ON THE GERMINATION AND VIGOR OF Chorisia glaziovii O. Kuntze SEEDS}

\begin{abstract}
Chorisia glaziovii O. Kuntze, a native species of Northeast Brazil belonging to the Bombacaceae, is widely used in folk medicines, the recuperation of degraded areas and the upholstery industry. The objective of this study was to evaluate the effects of saline stress and temperature on the germination and vigor of C. glaziovii seeds. Saline solutions were prepared using sodium chloride $(\mathrm{NaCl})$ as the solute, at concentrations of 0,0 (control); $1.5 ; 3.0 ; 4.5$ and 6.0 dS.m-1, diluted in distilled and deionized water. The seeds were distributed on the substrate to germinate at a constant $25^{\circ} \mathrm{C}, 30^{\circ} \mathrm{C}, 35^{\circ} \mathrm{C}$ and an alternating temperature of $20-30{ }^{\circ} \mathrm{C}$. The experimental design was randomized, with treatments distributed in a 5 x 4 factorial (five salinity levels and four temperatures), with four replications of 25 seeds. The percentage germination,
\end{abstract}

${ }^{1}$ Submetido em 23/08/2010. Aceito para publicação em 12/10/2010.

${ }^{2}$ Bióloga, doutoranda em Agronomia, Depto. de Fitotecnia, CCA-UFPB, roberta_biologa09@yahoo.com.br;

\footnotetext{
${ }^{3}$ Eng. Agr., Dr., Prof. Titular, Depto. de Fitotecnia, CCA-UFPB, Caixa postal 02, 58397-000, Areia - PB. ednaursulino@cca.ufpb.br;

${ }^{4}$ Eng. Agr., doutorandos em Agronomia, Depto. de Fitotecnia, CCAUFPB, eviogalindoea@yahoo.com.br; leandrabarrozo@yahoo.com.br.
} 
first count and germination speed index and seedling lengths (root and shoot) were evaluated. Increasing salt concentration in the substrate reduced the germination and vigor of C. glaziovii seeds, especially at temperatures of $30^{\circ} \mathrm{C}$ and $35^{\circ} \mathrm{C}$. At temperatures of $25^{\circ} \mathrm{C}$ and $20-30{ }^{\circ} \mathrm{C}$, the seed germination and vigor were less affected by water stress. Saline stress caused by $\mathrm{NaCl}$ up to the potential of $4.5 \mathrm{dS} . \mathrm{m}^{-1}$ did not affect the germination of C. glaziovii, which has developed a high tolerance to salinity.

Index terms: barriguda, forest seeds, salinity, seed analysis.

\section{INTRODUÇÃO}

A Chorisia glaziovii O. Kuntze é uma espécie florestal, nativa do Nordeste brasileiro, com presença na caatinga hipoxerófila e pertencente à família Bombacaceae, sendo popularmente denominada de barriguda, barriguda de espinho, paineira-branca, barriguda-do-pantanal, árvore-da-seda e árvore-da-lã. A árvore é ornamental de tronco bojudo, com floração branca muito vistosa, que ocorre entre setembro e outubro, período no qual perde totalmente a folhagem, dando lugar a exuberante florescimento, onde flores brancas lhe conferem beleza ímpar. As sementes são revestidas por fibra (lã), utilizada nas indústrias de estofados, no enchimento de travesseiros e colchões, assim como revestimentos em geral; ainda é excelente para plantios heterogêneos em recomposição de áreas degradadas, devido ao seu rápido crescimento (Lorenzi, 2002). Seus frutos são apreciados por periquitos e maritacas, que consomem a semente e a casca dos frutos, mesmo quando imaturos e, ainda há registros de uso da espécie na medicina popular para doenças do coração e pressão alta (Lucena et al., 2008).

Atualmente não há conhecimento suficiente para o manejo e análise de sementes da maioria das espécies florestais nativas do Nordeste do Brasil, de modo que se possa fornecer dados que possam caracterizar seus atributos físicos e fisiológicos (Lima et al., 2006). Nesse sentido, Larcher (2000) salientou que no estudo da germinação de sementes, o conhecimento sobre como o estresse influencia esse processo tem importância especial na ecofisiologia para avaliar os limites de tolerância e a capacidade de adaptação das espécies, pois os fatores abióticos interferem na germinação das sementes.

O processo germinativo se inicia com a absorção de água por embebição, porém, há necessidade de que a semente alcance um nível de hidratação que permita a reativação dos seus processos metabólicos para o estabelecimento das plântulas. Segundo Braga et al. (2009), o período germinativo é importante para a sobrevivência das espécies florestais, principalmente nos locais onde a disponibilidade de água é limitada durante um período do ano. Neste processo deve-se observar o grau de tolerância ao estresse salino, o qual depende da capacidade das plantas de minimizarem os efeitos da salinidade através de mecanismos específicos de adaptação (Larcher, 2000).

Um dos métodos mais difundidos para determinação da tolerância das plantas ao excesso de sais é a observação da porcentagem de germinação em substratos salinos (Lima e Torres, 2009), pois a salinidade afeta negativamente o crescimento e o desenvolvimento das plantas, onde seus efeitos dependem não só da espécie vegetal, mas também do tipo de sal existente no solo (Prisco, 1980). Conforme Goiz et al. (2008) a redução do poder germinativo, em comparação com o controle, serve como um indicador do índice de tolerância da espécie à salinidade. Nesse método, a habilidade para germinar indica, também, a tolerância das plantas aos sais em estádios subsequentes do desenvolvimento (Taiz e Zeiger, 2006).

Algumas pesquisas simulando o efeito do estresse salino na germinação e no vigor de sementes de espécies florestais têm sido desenvolvidas, a exemplo daquelas com sementes de Chorisia speciosa St. Hil. (Fanti e Perez, 2004), Schizolobium amazonicum Huber ex Ducke (Braga et al., 2008), Enterolobium schomburgkii Benth. (Braga et al., 2009), Gliricidia sepium (Jacq.) Steud. (Farias et al., 2009) e Zizyphus joazeiro Mart. (Lima e Torres, 2009).

Outro fator ambiental que pode interferir na capacidade germinativa de sementes das espécies é a temperatura, cujos efeitos também podem ser avaliados a partir de mudanças ocasionadas na porcentagem e velocidade de germinação ao longo do tempo de incubação (Fonseca e Perez, 1999). A germinação ocorre em determinados limites de temperatura, dentro das quais existe uma temperatura em que o processo ocorre com maior eficiência (Carvalho e Nakagawa, 2000). Segundo Marcos Filho (2005) as variações de temperatura afetam 
a velocidade, a percentagem e a uniformidade de germinação. Portanto, a temperatura ótima é aquela que possibilita a combinação mais eficiente entre a porcentagem e a velocidade de germinação.

Apesar de haver grande diversidade de espécies nativas no Brasil, ainda há uma carência de estudos relacionados ao processo germinativo e, para as sementes de Chorisia glaziovii, ainda não estão estabelecidos os critérios para a realização do teste de germinação. Desta forma, o presente trabalho foi desenvolvido com o objetivo de avaliar o efeito do estresse salino e de diferentes temperaturas na germinação e vigor das sementes de Chorisia glaziovii.

\section{MATERIAL E MÉTODOS}

O experimento foi conduzido no Laboratório de Análise de Sementes (LAS), do Centro de Ciências Agrárias da Universidade Federal da Paraíba, (CCA - UFPB), Areia - PB, no período de janeiro a fevereiro de 2010. Os frutos de Chorisia glaziovii foram colhidos diretamente de cinco árvores matrizes localizadas no Sítio Bosque, município de Campina Grande - PB. Após a colheita os frutos foram levados ao LAS, onde as sementes foram beneficiadas mediante debulha manual e remoção da lã e mantidas em laboratório, à sombra, para secagem natural por cinco dias. Em seguida foram realizados os seguintes testes e determinações:

O teor de água foi determinado com a utilização de quatro subamostras de 25 sementes em cada tratamento, sendo colocadas em estufa a $105 \pm 3{ }^{\circ} \mathrm{C}$, por 24 horas, seguindo as recomendações de Brasil (2009) e, os resultados expressos em porcentagem.

$\mathrm{Na}$ simulação do estresse salino utilizou-se como soluto o cloreto de sódio $(\mathrm{NaCl})$, nas concentrações: 0,0 (controle); 1,$5 ; 3,0 ; 4,5$ e 6,0 dS.m ${ }^{-1}$ diluídas em água destilada e deionizada, cujo valor da condutividade elétrica das soluções foi verificado com auxílio de um condutivímetro. No nível zero foi utilizada apenas água destilada e deionizada para umedecer o substrato. Os valores de condutividade elétrica das soluções de cloreto de sódio foram obtidos pela expressão de Richards (1954), sendo, $\frac{C S=0,001 \text { (CEs - CEan) Peq }}{0,97}$

onde: $\mathrm{CS}=$ concentração $\left(\mathrm{g} . \mathrm{L}^{-1}\right)$; CEs $=$ condutividade elétrica a 25 ${ }^{\circ} \mathrm{C}$ da água da mistura $\left(\mathrm{dS} . \mathrm{m}^{-1}\right)$; CEan $=$ condutividade elétrica da água utilizada $\left(\mathrm{dS} . \mathrm{m}^{-1}\right) ; \mathrm{Peq}=$ peso equivalente do sal utilizado e $0,97=$ porcentagem de pureza estimada do cloreto de sódio.

No teste de germinação, para cada tratamento utilizou-se 100 sementes, as quais foram divididas em quatro repetições de 25 sementes cada. As sementes foram distribuídas sobre duas folhas de papel toalha, cobertas com uma terceira e organizadas em forma de rolo. O papel toalha foi umedecido com as soluções de $\mathrm{NaCl}$ supracitadas na quantidade equivalente a 3,0 vezes a massa do papel não hidratado, sem adição posterior da solução, além do tratamento com água destilada e deionizada, representando a testemunha, na mesma quantidade citada anteriormente. Os rolos foram acondicionados em sacos plásticos transparentes, de 0,04 mm de espessura, com a finalidade de evitar a perda de água por evaporação.

O teste de germinação foi conduzido em germinador tipo Biochemical Oxigen Demand (B.O.D.) regulado para os regimes de temperatura constante de $25{ }^{\circ} \mathrm{C}, 30{ }^{\circ} \mathrm{C}$ e $35{ }^{\circ} \mathrm{C}$ e alternada de $20-30{ }^{\circ} \mathrm{C}$, com fotoperíodo de oito horas, utilizando lâmpadas fluorescentes tipo luz do dia (4 x $20 \mathrm{~W}$ ). As avaliações foram efetuadas diariamente após a instalação do teste, por um período de 12 dias, quando o experimento foi encerrado. As contagens foram realizadas considerando-se como sementes germinadas aquelas que emitiram a raiz primária e a parte aérea (plântulas normais).

A primeira contagem foi realizada juntamente com o teste de germinação, determinando-se a porcentagem de plântulas normais no quinto dia após a instalação do teste e, os resultados foram expressos em porcentagem.

$O$ índice de velocidade de germinação (IVG) foi realizado juntamente com o teste de germinação, onde se efetuou contagens diárias das plântulas normais, dos cinco aos 12 dias, à mesma hora e, o índice de velocidade de germinação calculado empregando-se a fórmula proposta por Maguire (1962), onde: $I V G=\frac{G_{1}}{N_{1}}+\frac{G_{2}}{N_{2}}+\ldots+\frac{G_{n}}{G_{n}} \quad$ em que IVG = índice velocidade de germinação; $G_{1}, G_{2}$ e $G_{n}$ = número de sementes germinadas a cada dia; $\mathrm{N}_{1}, \mathrm{~N}_{2}, \ldots$ $\mathrm{N}_{\mathrm{n}}$ = número de dias decorridos da semeadura a primeira, segunda e última contagem.

Após a contagem final do teste de germinação, as plântulas normais de cada tratamento e repetição foram medidas (raiz e parte aérea), com auxílio de uma régua graduada em centímetros, sendo os resultados expressos em cm.plântula ${ }^{-1}$.

O delineamento experimental utilizado foi o inteiramente ao acaso, com os tratamentos distribuídos em esquema fatorial 5 × 4 (níveis de salinidade e temperaturas), 
em quatro repetições. Os dados, não transformados, foram submetidos à análise de variância e de regressão polinomial, testando os modelos linear e quadrático, onde se selecionou o modelo significativo de maior ordem $\left(\mathrm{R}^{2}\right)$.

\section{RESULTADOS E DISCUSSÃO}

Os resultados obtidos com as sementes de Chorisia glaziovii submetidas ao estresse salino nas diferentes temperaturas indicaram que a interação entre esses fatores exerceram influência sobre a porcentagem de germinação (Figura 1). Em todas as temperaturas, a porcentagem de germinação reduziu à medida que houve aumento na concentração das soluções salinas, sendo que os maiores porcentuais de germinação $(86 \%, 68 \%$ e $75 \%)$ foram obtidos com sementes submetidas às temperaturas de 25 ${ }^{\circ} \mathrm{C}, 30{ }^{\circ} \mathrm{C}$ e $20-30{ }^{\circ} \mathrm{C}$ no nível zero de salinidade (controle). No entanto, a partir deste nível a germinação foi afetada negativamente, atingindo $38 \%, 14 \%$ e $35 \%\left(25^{\circ} \mathrm{C}, 30{ }^{\circ} \mathrm{C}\right.$ e 20-30 ${ }^{\circ} \mathrm{C}$, respectivamente), no nível de $6,0 \mathrm{dS} \cdot \mathrm{m}^{-1}$.
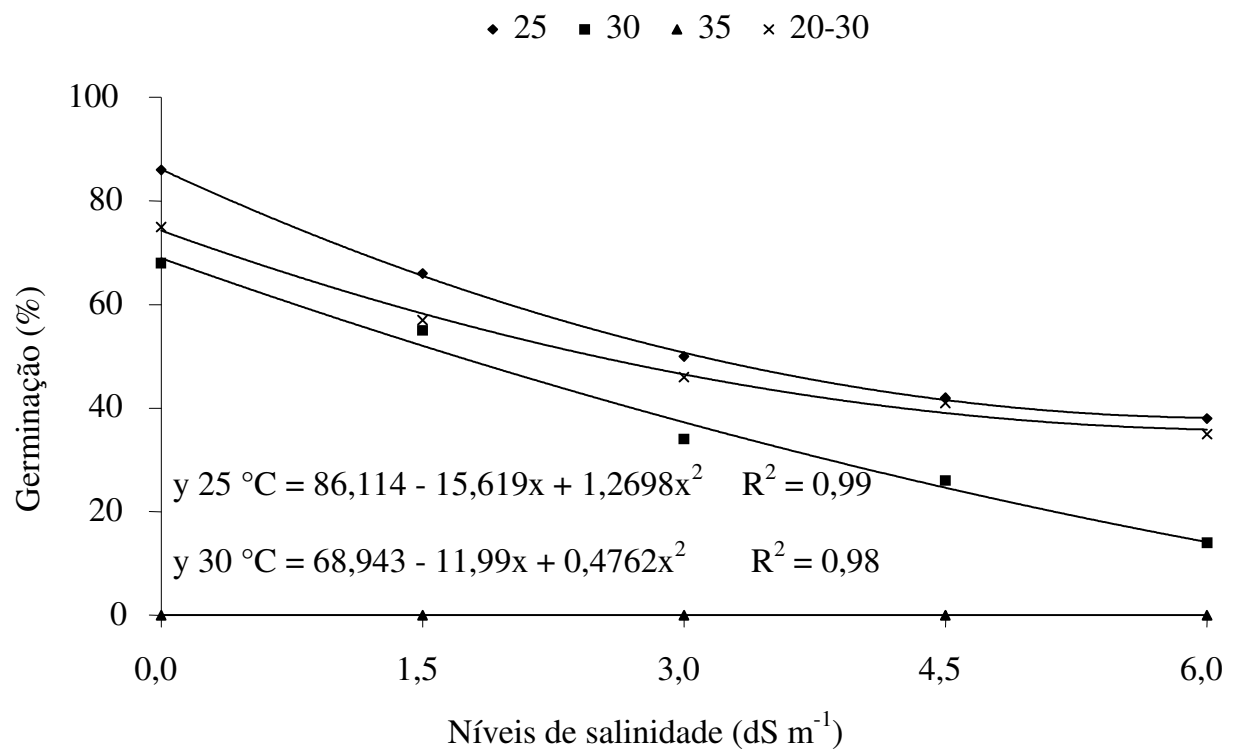

FIGURA 1. Germinação (\%) de sementes de Chorisia glaziovii 0 . Kuntze submetidas ao estresse salino induzido por $\mathrm{NaCl}\left(0,0 ; 1,5 ; 3,0 ; 4,5 ; 6,0 \mathrm{dS} . \mathrm{m}^{-1}\right)$ sob diferentes temperaturas $\left(25^{\circ} \mathrm{C} ; 30{ }^{\circ} \mathrm{C} ; 35^{\circ} \mathrm{C} ; 20-30{ }^{\circ} \mathrm{C}\right)$.

Quando as sementes de C. glaziovii foram submetidas a temperatura de $35{ }^{\circ} \mathrm{C}$ registrou-se uma mortalidade de $100 \%$ na última contagem do teste (Figura 1). Esse fato demonstra que essa temperatura não deve ser utilizada para a condução do teste de germinação das sementes, possivelmente por acelerar a respiração e, consequentemente, o processo de deterioração das sementes. Deve-se ressaltar ainda, que mesmo havendo redução na porcentagem de germinação das sementes de C. glaziovii, as mesmas continuam germinando mesmo com o aumento dos níveis de salinidade. Considerando o tamanho do banco de sementes que essa espécie forma, porcentuais de germinação dessa natureza conferem à espécie a capacidade de formar populações significativas, mesmo em ambientes salinos. Estes resultados podem ser explicados devido à influência da temperatura no processo germinativo, pois as temperaturas mais baixas $\left(25^{\circ} \mathrm{C}\right.$ e $\left.20-30{ }^{\circ} \mathrm{C}\right)$ podem ter reduzido o metabolismo das sementes, retardando assim a germinação. Por outro lado, a temperatura mais elevada $\left(35^{\circ} \mathrm{C}\right)$ pode ter provocado desintegração das estruturas protéicas e, em conjunto com o efeito tóxico e a seca fisiológica causada pelos níveis de sais possivelmente provocaram redução na germinação das sementes.

$\mathrm{O}$ excesso dos íons $\mathrm{Na}^{+}$e $\mathrm{Cl}^{-}$pode ter sido responsável pela redução na germinação, uma vez que os mesmos tendem a causar a diminuição da intumescência protoplasmática, (os íons em solução inicialmente causam diminuição da intumescência, e somente após a sua absorção e acumulação nos vacúolos e apoplasto é que a taxa de absorção de água é normalizada) (Ferreira e Borghetti, 2004), afetando a atividade enzimática, 
resultando, principalmente, na produção inadequada de energia por distúrbios na cadeia respiratória (Larcher, 2000), além do efeito tóxico, resultante da concentração de íons no protoplasma (Tobe e Omasa, 2000). Com a elevação da concentração salina na solução do solo ocorre um aumento da pressão osmótica e, logo a planta não absorve a água do solo, ocasionando distúrbios fisiológicos e morfológicos que dificultam a sobrevivência da planta ao estresse (Taiz e Zeiger, 2006).

Em sementes de Anadenanthera pavonina L. submetidas a diferentes potenciais osmóticos de $\mathrm{NaCl}$, na temperatura de $25^{\circ} \mathrm{C}$ ocorreu germinação até o potencial de -1,4 MPa (Fonseca e Perez, 1999). Para sementes de Apuleia leiocarpa (Vog.) Macbr. ocorreu germinação até o potencial -0,4 MPa, havendo redução da porcentagem de germinação à medida que os potenciais se tornaram mais negativos (Henicka et al., 2006). Comportamento diferente ocorreu em Senna spectabilis (DC) Irwin et Barn. (Jeller e Perez, 2001) e em Chorisia speciosa St. Hil. (Fanti e Perez, 2004), cuja germinação não foi reduzida significativamente até o potencial de $-0,4 \mathrm{MPa}$. A porcentagem de germinação de sementes de Enterolobium schomburgkii (Benth.) Benth reduziu significativamente em soluções de $\mathrm{NaCl}$ com potencial a partir de -0,2 $\mathrm{MPa}$ (Braga et al., 2009). Nas soluções de $\mathrm{NaCl}$, o decréscimo significativo da germinação das sementes de Zizyphus joazeiro Mart. ocorreu com potenciais a partir de $-0,3$ MPa (Lima e Torres, 2009).

Os dados referentes a primeira contagem de germinação das sementes de C. glaziovii estão na Figura 2 , pelos quais se observa que na temperatura de $30{ }^{\circ} \mathrm{C}$ o porcentual de germinação aos cinco dias tornou-se nulo no nível 4,5 dS. $\mathrm{m}^{-1}$ de salinidade. Verifica-se ainda, que além da salinidade ser prejudicial para as sementes, esta temperatura $\left(30{ }^{\circ} \mathrm{C}\right)$ contribui para a redução da germinação. Para as temperaturas de $25{ }^{\circ} \mathrm{C}$ e $20-30{ }^{\circ} \mathrm{C}$ a porcentagem de germinação decresceu à medida que aumentou o nível de salinidade das soluções, passando de $30 \%$ e $23 \%$ no potencial 0,0 (controle) para $4 \%$ e $2 \%$, respectivamente no nível 6,0 dS.m ${ }^{-1}$ de $\mathrm{NaCl}$.

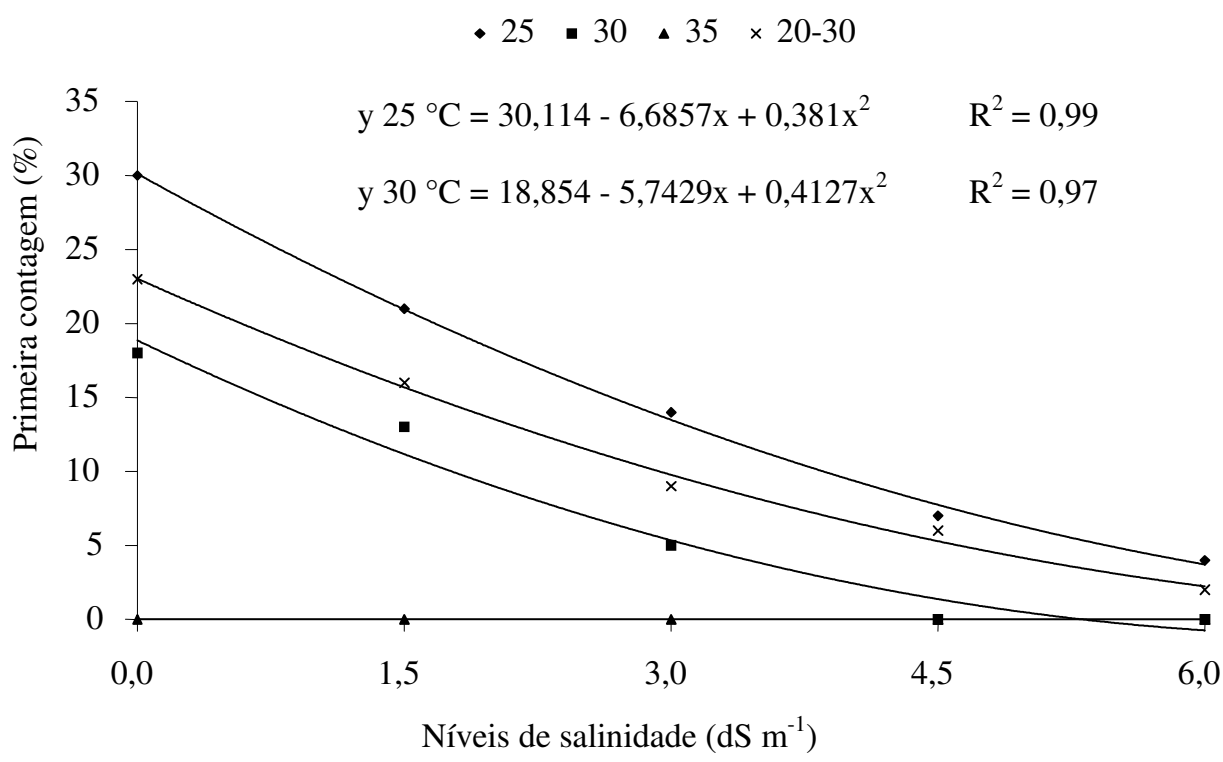

FIGURA 2. Primeira contagem de germinação de sementes de Chorisia glaziovii O. Kuntze submetidas ao estresse salino induzido por $\mathrm{NaCl}\left(0,0 ; 1,5 ; 3,0 ; 4,5 ; 6,0 \mathrm{dS} . \mathrm{m}^{-1}\right)$ sob diferentes temperaturas $\left(25^{\circ} \mathrm{C} ; 30{ }^{\circ} \mathrm{C}\right.$; $\left.35^{\circ} \mathrm{C} ; 20-30{ }^{\circ} \mathrm{C}\right)$.

A redução na porcentagem de germinação e o atraso no início do processo germinativo com o aumento do estresse salino podem estar relacionados com a seca fisiológica produzida, pois quando existe aumento da concentração de sais no meio germinativo, há uma diminuição do potencial osmótico e, consequentemente, uma redução do potencial hídrico (Fanti et al., 2004). E conforme ressalta Tôrres et al. (2004) ocorre o desbalanço nutricional, ocasionado pela 
inibição da absorção e transporte de nutrientes, bem como, os efeitos tóxicos de íons, particularmente cloro e sódio. Esta redução pode afetar a cinética de absorção de água pelas sementes (efeito osmótico), como também elevar a níveis tóxicos a concentração de íons no embrião (efeito tóxico) (Cramer et al., 1986; Tobe e Omasa, 2000).

De forma semelhante ao que ocorreu na germinação e na primeira contagem de germinação, o índice de velocidade de germinação das sementes de C. glaziovii foi bastante afetado pelo acréscimo dos níveis de salinidade das soluções de $\mathrm{NaCl}$ (Figura 3). Os maiores índices de velocidade de germinação ocorreram no nível zero de salinidade para as sementes incubadas nas temperaturas de $25{ }^{\circ} \mathrm{C}$ e $20-30{ }^{\circ} \mathrm{C}$, com valores de 3,4 e 3,2 , respectivamente; posteriormente ocorreram reduções significativas para valores abaixo de 2,04 e 1,85, quando as sementes foram submetidas ao nível de salinidade de 6 $\mathrm{dS} . \mathrm{m}^{-1}$ nas referidas temperaturas. Nas sementes incubadas na temperatura de $30{ }^{\circ} \mathrm{C}$, a redução da velocidade de germinação foi mais significativa com um índice de 2,63 no nível $0,0 \mathrm{dS} . \mathrm{m}^{-1}$ o qual chegou a 1,29 no potencial de 6,0 dS.m-1 (Figura 3).
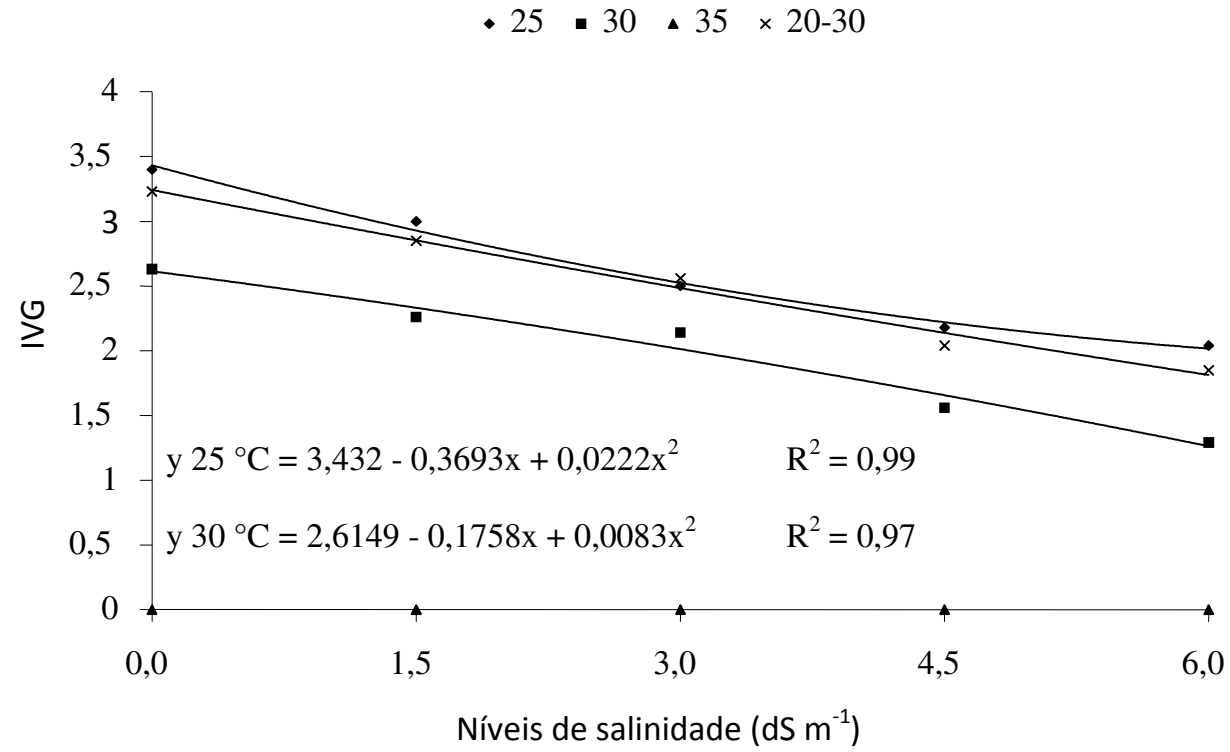

FIGURA 3. Índice de velocidade de germinação de sementes de Chorisia glaziovii $\mathrm{O}$. Kuntze submetidas ao estresse salino induzido por $\mathrm{NaCl}\left(0,0 ; 1,5 ; 3,0 ; 4,5 ; 6,0 \mathrm{dS} . \mathrm{m}^{-1}\right)$ sob diferentes temperaturas $\left(25^{\circ} \mathrm{C}\right.$; $30{ }^{\circ} \mathrm{C} ; 35^{\circ} \mathrm{C} ; 20-30{ }^{\circ} \mathrm{C}$ ).

O índice de velocidade de germinação foi eficiente na indicação dos efeitos negativos, tanto dos níveis de sais como das temperaturas, uma vez que o aumento nas concentrações salinas proporcionou redução na velocidade de germinação. Com relação às temperaturas observou-se que estas também afetaram a velocidade de germinação das sementes, sendo que a temperatura de $30{ }^{\circ} \mathrm{C}$ foi mais prejudicial, independente dos níveis de sais utilizados.

$\mathrm{O}$ efeito da salinidade no processo germinativo de sementes de Prosopis juliflora (Sw.) (Perez e Tambelini, 1995) e de Pterogyne nitens Tull (Nassif e Perez, 1997) foi mais acentuado na velocidade do que na porcentagem de germinação. O índice de velocidade de germinação de sementes de Stylosanthes capitata Vog. foi afetado pelos níveis de salinidade aplicados, sendo o efeito mais intenso em salinidade a partir de 2,5 dS m-1 (Oliveira et al., 2008).

De modo similar ao que ocorreu nas variáveis anteriores, o comprimento da raiz e parte aérea de plântulas de C. glaziovii também foi afetado à medida que houve aumento dos níveis de salinidade, nas diferentes temperaturas testadas (Figura 4 e 5). As plântulas originadas das sementes submetidas às temperaturas de $25^{\circ} \mathrm{C}$ e $20-30{ }^{\circ} \mathrm{C}$ no tratamento controle expressaram os maiores comprimentos de raiz $(5,46$ e 4,46 cm, respectivamente) (Figura 4). Para as plântulas oriundas de sementes submetidas à temperatura de $30{ }^{\circ} \mathrm{C}$, no 
tratamento controle houve redução nos comprimentos (4,1 para 1,78 cm), no nível de salinidade de $6,0 \mathrm{dS} \cdot \mathrm{m}^{-1}$. A maior habilidade da radícula para crescer em condições mais frias facilitaria a fixação das plântulas, a captura e a translocação dos recursos disponíveis para as mesmas crescerem (Roman et al., 1999), pois a temperatura fora da faixa ótima reduz a taxa de crescimento da parte aérea e radicular (Roman et al., 2000).
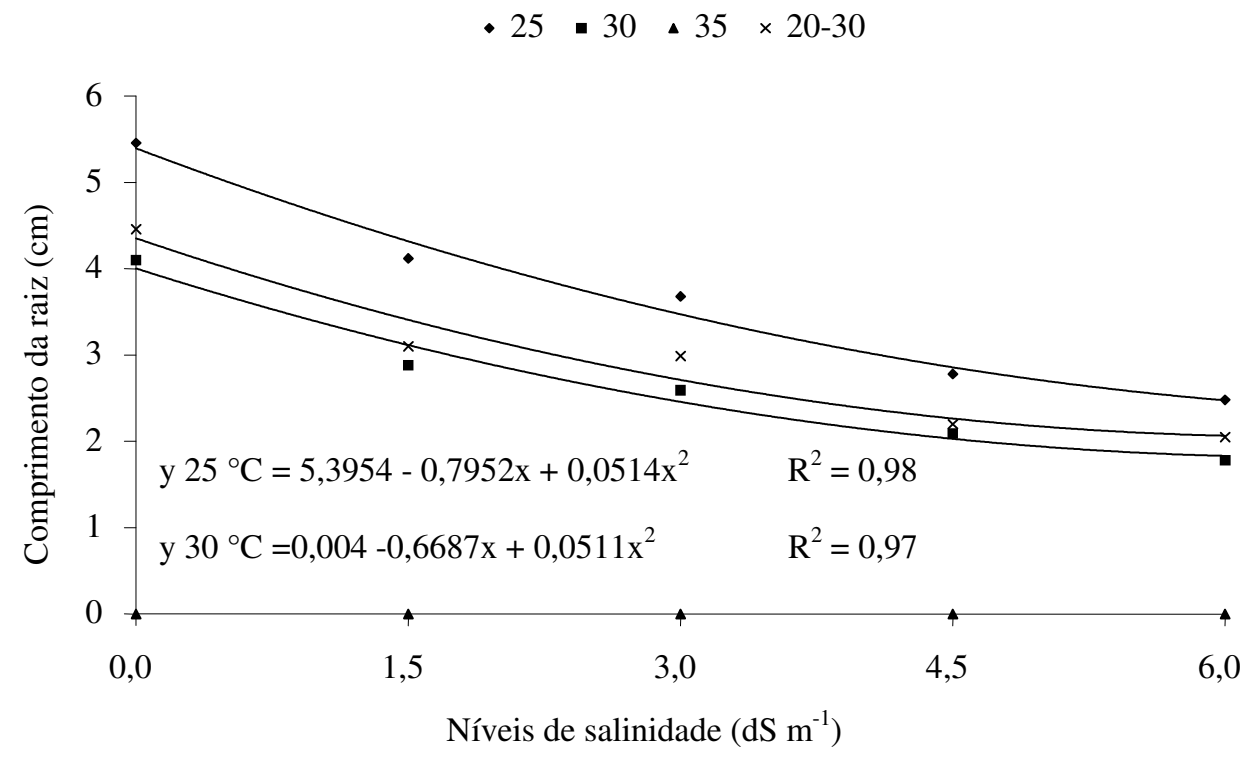

FIGURA 4. Comprimento da raiz primária $(\mathrm{cm})$ de plântulas de Chorisia glaziovii 0 . Kuntze oriundas de sementes submetidas ao estresse salino induzido por $\mathrm{NaCl}\left(0,0 ; 1,5 ; 3,0 ; 4,5 ; 6,0\right.$ dS.m $\left.{ }^{-1}\right)$ sob diferentes temperaturas $\left(25^{\circ} \mathrm{C} ; 30^{\circ} \mathrm{C} ; 35^{\circ} \mathrm{C} ; 20-30{ }^{\circ} \mathrm{C}\right)$.

Para a parte aérea de plântulas de C. glaziovii verificouse comportamento semelhante ao observado na raiz, onde o melhor desempenho foi registrado nas temperaturas de $25^{\circ} \mathrm{C}$ e $20-30{ }^{\circ} \mathrm{C}$ no tratamento controle $(8,47$ e $7,68 \mathrm{~cm})$, e na temperatura de $30^{\circ} \mathrm{C}$ as plântulas apresentavam 6,99 $\mathrm{cm}$ no mesmo potencial $(0,0)$. Ao serem submetidas ao potencial de $6,0 \mathrm{dS} . \mathrm{m}^{-1}$ as raízes das plântulas atingiram 3,64; 2,92 e $3,14 \mathrm{~cm}$, respectivamente nas temperaturas de $25{ }^{\circ} \mathrm{C}, 30{ }^{\circ} \mathrm{C}$ e $20-30{ }^{\circ} \mathrm{C}$ (Figura 5). Dentre todas as temperaturas avaliadas, aquela de $25{ }^{\circ} \mathrm{C}$ foi a que proporcionou o maior comprimento de plântulas (raiz e parte aérea), sendo adequada para o desenvolvimento das mesmas, independente das concentrações de sais utilizadas.

No desenvolvimento das plântulas, verificou-se ocorrência de maior porcentagem de plântulas anormais em soluções de concentrações salinas mais altas, a partir de $4,5 \mathrm{dS} . \mathrm{m}^{-1}$. Isto se justifica, pois a presença de sais interfere nos processos de divisão e crescimento das células e disponibilização das reservas indispensáveis à germinação (Mayer e Poljakoff-Mayber, 1989).

As plântulas de Triplaris americana L. originadas de sementes submetidas a $35{ }^{\circ} \mathrm{C}$ foram mais afetadas pelo estresse salino, cujo comprimento foi significativamente menor em relação aquelas submetidas às temperaturas de $25{ }^{\circ} \mathrm{C}, 30{ }^{\circ} \mathrm{C}$ e $20-30{ }^{\circ} \mathrm{C}$ demonstrando efeito negativo da alta temperatura, aliada ao estresse salino no desenvolvimento de plântulas (Cruz, 2009). Lima e Torres (2009) estudando sementes de Zizyphus joazeiro Mart., observaram que houve diferença significativa no crescimento da parte aérea entre a testemunha e os demais tratamentos, notando-se que a partir do potencial osmótico $-0,6 \mathrm{MPa}$ de $\mathrm{NaCl}$ não ocorreu crescimento significativo da plântula.

O fato da germinação e do vigor das sementes de C. glaziovii terem sido afetados negativamente não quer dizer que esta espécie não tenha potencial para vegetar em condições salinas com concentrações similares 
ao do intervalo utilizado neste trabalho. E com os resultados obtidos com o estresse salino em sementes de C. glaziovii verifica-se a importância ecológica, pois demonstram que as sementes desta espécie não possuem exigências especiais, quanto concentração salina, para a sua geminação, principalmente nas fases inicias do seu ciclo de vida. Este alto limite de tolerância ao estresse salino, na temperatura de $25{ }^{\circ} \mathrm{C}$ e $20-30{ }^{\circ} \mathrm{C}$ confere a C. glaziovii um caráter adaptativo, propiciando elevada capacidade de estabelecimento de suas plântulas em áreas onde as mais sensíveis à salinidade não são capazes de sobreviver.

- $25 \cdot 30 \triangle 35 \times 20-30$

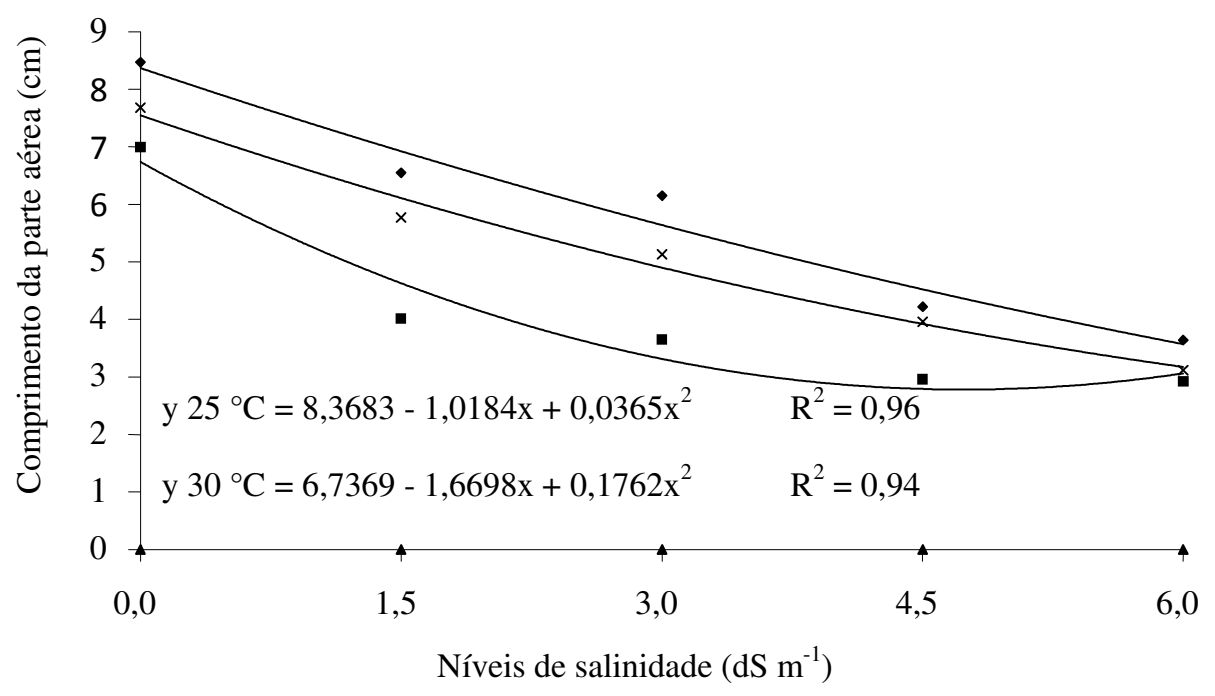

FIGURA 5. Comprimento de parte aérea $(\mathrm{cm})$ de plântulas de Chorisia glaziovii O. Kuntze oriundas de sementes submetidas ao estresse hídrico induzido por $\mathrm{NaCl}\left(0,0 ; 1,5 ; 3,0 ; 4,5 ; 6,0 \mathrm{dS}^{-\mathrm{m}^{-1}}\right)$ sob diferentes temperaturas $\left(25^{\circ} \mathrm{C} ; 30^{\circ} \mathrm{C} ; 35^{\circ} \mathrm{C} ; 20-30{ }^{\circ} \mathrm{C}\right)$.

\section{CONCLUSÕES}

O aumento da concentração salina no substrato reduz a germinação e o vigor das sementes de Chorisia glaziovii O. Kuntze, especialmente nas temperaturas de $30^{\circ} \mathrm{C}$ e $35^{\circ} \mathrm{C}$;

Nas temperaturas de $25^{\circ} \mathrm{C}$ e $20-30^{\circ} \mathrm{C}$ a germinação e o vigor das sementes são menos afetados pela salinidade;

O estresse salino ocasionado por $\mathrm{NaCl}$ até o potencial de $4,5 \mathrm{dS} . \mathrm{m}^{-1}$ não afeta o desempenho germinativo de sementes de C. glaziovii, a qual desenvolveu elevada tolerância à salinidade.

\section{REFERÊNCIAS}

BRAGA, L.F.; SOUSA, M.P.; CESARO, A.S.; LIMA, G.P.P.; GONÇALVES, A.N. Germinação de sementes de pinho-cuiabano sob deficiência hídrica com diferentes agentes osmóticos. Scientia Forestalis, v.36, n.78, p.157163, 2008. http://www.ipef.br/publicacoes/scientia/nr78/ cap08.pdf

BRAGA, L.F.; SOUSA, M.P.; ALMEIDA, T.A. Germinação de sementes de Enterolobium schomburgkii (Benth.) Benth. submetidas a estresse salino e aplicação de poliamina. Revista Brasileira de Plantas Medicinais, v.11, n.1, p.63-70, 2009. http://www.ibb.unesp.br/servicos/ publicacoes/rbpm/pdf_v11_n1_2009/artigo11_p63-70.pdf

BRASIL. Ministério da Agricultura, Pecuária e Abastecimento. Regras para análise de sementes. Ministério da Agricultura, Pecuária e Abastecimento. Secretaria de Defesa Agropecuária. Brasília, DF: Mapa/ ACS, 2009. 395p.

CARVALHO, N.M.; NAKAGAWA, J. Sementes: ciência, tecnologia e produção. 4.ed. Jaboticabal: FUNEP, 2000. 588p.

CRAMER, G.R.; LÄUCHLI, A.; EPSTEIN, E. Effects of $\mathrm{NaCl}$ and $\mathrm{CaCl}_{2}$ on ion activities in complex nutrient solutions and root growth of cotton. Plant Physiology, 
v.81, n.3, p.792-797, 1986. http://www.ncbi.nlm.nih.gov/ pmc/articles/PMC1075428/

CRUZ, J.C.M. Qualidade fisiológica de sementes de Triplaris americana L. submetidas ao estresse hídrico e salino em diferentes temperaturas. 2009, 29f. Monografia (Graduação em Agronomia) - Universidade federal da Paraíba, Areia. 2009.

FANTI, S.C.; PEREZ, S.C.J.G.A. Processo germinativo de sementes de paineira sob estresses hídrico e salino. Pesquisa Agropecuária Brasileira, v.39, n.9, p.903-909, 2004. http://www.scielo.br/pdf/pab/v39n9/22034.pdf

FARIAS, S.G.G.; FREIRE, A.L.O.; SANTOS, D.R.S.; BAKKE, I.A.; SILVA, R.B. Efeitos dos estresses hídrico e salino na germinação de sementes de gliricidia [Gliricidia sepium (Jacq.) Steud.]. Revista Caatinga, v.22, n.4, p.152157, 2009. http://caatinga.ufersa.edu.br/index.php/sistema/ article/viewFile/1329/754

FERREIRA, A.G.; BORGUETTI, F. Germinação: do básico ao aplicado. Porto Alegre: Artmed, 2004.

FONSECA, S.C.L.; PEREZ, S.C.J.G.A. Efeito de sais e da temperatura na germinação de sementes de olho-dedragão (Anadenanthera pavonina L. - Fabaceae). Revista Brasileira de Sementes, v.21, n.2, p.70-77, 1999. http:// www.abrates.org.br/revista/artigos/1999/v21n2/artigo11. pdf

GÓIS, V.A.; TORRES, S.B.; PEREIRA, R.A. Germinação de sementes de maxixe submetidas a estresse salino. Caatinga, v.21, n.4, p.64-67, 2008. http://caatinga.ufersa. edu.br/index.php/sistema/article/viewFile/798/412

HENICKA, G.S.; BRAGA, L.F.; SOUSA, M.P.; CARVALHO, M.A.C. Germinação de sementes de Apuleia leiocarpa (Vogel.) J.F. Macbr.: temperatura, fotoblastismo e estresse salino. Revista de Ciências Agro-Ambientais, v.4, n.1, p.37-46, 2006. http://www.unemat.br/revistas/ rcaa/docs/vol4/5_artigo_v4.pdf

JELLER, H.; PEREZ, S.C.J.G.A. Efeitos dos estresses hídrico e salino e da ação de giberelina em sementes de Senna spectabilis. Ciência Florestal, v.11, n.1, p.93-104, 2001. http://redalyc.uaemex.mx/redalyc/pdf/534/53411109.pdf

LARCHER, W. Ecofisiologia vegetal. São Carlos: Rima, 2000. 531p.

LIMA, B.G.; TORRES, S.B. Estresses hídrico e salino na germinação de sementes de Zizyphus joazeiro Mart. (Rhamnaceae). Revista Caatinga, v.22, n.4, p.93-99, 2009. http://caatinga.ufersa.edu.br/index.php/sistema/ article/viewFile/1455/746
LIMA, J.D. ALMEIDA, C.C.; DANTAS, V.A.V.; SILVA, B.M.S.; MORAES, W. Efeito da temperatura e dos substratos na germinação de sementes de Caesalpinia ferrea Mart. ex. Tul. (Leguminosae). Revista Árvore, v.30, n.4, p.513-518, 2006. http://www.scielo.br/pdf/rarv/ v30n4/31671.pdf

LORENZI, H. Árvores brasileiras: manual de identificação e cultivo de plantas arbóreas nativas do Brasil. Nova Odessa: Instituto Plantarum, 4.ed. v.1, 2002. 351p.

LUCENA, R.F.P.; NASCIMENTO, V.T.; ARAÚJO, E.L.; ALBUQUERQUE, U.P. Local uses of native plants in area of caatinga vegetation Pernambuco - NE, Brazil. Ethnobotany Research and Applications, v.6, p.3-13, 2008. http://www.ecologiavegetalufpb.net/artigo\%20 nal $\% 20$ e $\% 20$ vivy $\% 20$ caruaru.pdf

MAGUIRE, J.D. Speed of germination-aid in selection and evaluation for seedling emergence vigor. Crop Science, v.2, n.2, p.176-177, 1962.

MARCOS FILHO, J. Fisiologia de sementes de plantas cultivadas. Piracicaba: FEALQ, 2005. 495p.

MAYER, A. M.; POLJAKOFF-MAYBER, A. The germination of seeds. 4.ed. Oxford: Pergamon Press, 1989. 270p.

NASSIF, M.L.; PEREZ, S.C.J.G.A. Germinação de sementes de amendoim-do-campo (Pterogyne nitens Tul. - Fabaceae - Caesalpinoideae) submetidas a diferentes condições de estresse hídrico e salino. Revista Brasileira de Sementes, v.19, n.2, p.142-149, 1997. http://www. abrates.org.br/revista/artigos/1997/v19n2/artigo01.pdf

OLIVEIRA, F.A. MEDEIROS, J.F. OLIVEIRA, M.K.T. LIMA, C.J.G.S. GALVÃO, D.C. Efeito da água salina na germinação de Stylosanthes capitata Vogel. Revista Verde, v.3, n.1, p.77-82, 2008. http://www.gvaa.com.br/ revista/index.php/RVADS/article/view/98/116

PEREZ, S.C.J.G.A.; TAMBELINI, M. Efeito dos estresses salino e hídrico e do envelhecimento precoce na germinação de algarobeira. Pesquisa Agropecuária Brasileira, v.30, n.11, p.1289-1295, 1995.http://webnotes.sct.embrapa.br/ pab/pab.nsf/1369aa7a4f8bbb9d03256508004f4e1d/76e0ce f48f41350f032567db004b4c4e/\$FILE/pab95_02_nov.pdf

PRISCO, J.T. Alguns aspectos da fisiologia do estresse salino. Revista Brasileira Botânica, v.3, n.1, p.85-94, 1980

RICHARDS, L.A. Diagnóstico y rehabilitacion de suelos salinos y sádicos. México: Departamento de Agricultura de los Estados Unidos de América. 1954, 172p. (Manual de agricultura, 60). 
ROMAN, E.S.; THOMAS, A.G.; MURPHY, S.D.; SWANTON, C.J. Modeling germination and seedling elongation of common lambsquarters (Chenopodium album). Weed Science, v.47, n.2, p.149-155, 1999. http:// www.jstor.org/pss/4046190

ROMAN, E.S.; MURPHY, S.D.; SWANTON, C. Simulation of Chenopodium album seedling emergence. Weed Science, v.48, n.2, p.217-224, 2000. http://www. jstor.org/pss/4046258
TAIZ, L.; ZEIGER, E. Fisiologia vegetal. Porto Alegre: Artmed, 2006. 719p.

TOBE, K.; LI, X.; OMASA, K. Seed germination and radicle growth of a halophyte, Kalidium caspicum (Chenopodiaceae). Annals of Botany, v.85, n.3, p.391-396, 2000. http://aob.oxfordjournals.org/cgi/reprint/85/3/391

TÔRRES, A.N.L.; PEREIRA, P.R.G.; TÔRRES, J.T.; GALLOTTI, G.J.M.; PILATI, J.A.; REBELO, J.A.; HENKELS, H.A salinidade e suas implicações no cultivo de plantas. Florianópolis: Epagri, 2004. 54p. (Epagri. Documentos, 215). 